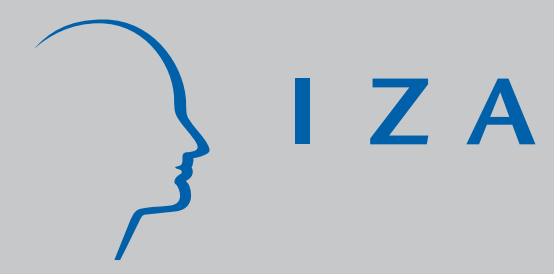

IZA DP No. 924

Employment Effects of Dispersal Policies on Refugee Immigrants, Part I: Theory

Anna Piil Damm

Michael Rosholm

November 2003 


\title{
Employment Effects of Dispersal Policies on Refugee Immigrants, Part I: Theory
}

\author{
Anna Piil Damm \\ CIM, Aarhus School of Business \\ Michael Rosholm \\ Institute of Local Government Studies (AKF), \\ University of Aarhus and IZA Bonn
}

\section{Discussion Paper No. 924 \\ November 2003}

\author{
IZA \\ P.O. Box 7240 \\ D-53072 Bonn \\ Germany \\ Tel.: +49-228-3894-0 \\ Fax: +49-228-3894-210 \\ Email: iza@iza.org
}

This Discussion Paper is issued within the framework of IZA's research area Mobility and Flexibility of Labor. Any opinions expressed here are those of the author(s) and not those of the institute. Research disseminated by IZA may include views on policy, but the institute itself takes no institutional policy positions.

The Institute for the Study of Labor (IZA) in Bonn is a local and virtual international research center and a place of communication between science, politics and business. IZA is an independent, nonprofit limited liability company (Gesellschaft mit beschränkter Haftung) supported by Deutsche Post World Net. The center is associated with the University of Bonn and offers a stimulating research environment through its research networks, research support, and visitors and doctoral programs. IZA engages in (i) original and internationally competitive research in all fields of labor economics, (ii) development of policy concepts, and (iii) dissemination of research results and concepts to the interested public. The current research program deals with (1) mobility and flexibility of labor, (2) internationalization of labor markets, (3) welfare state and labor market, (4) labor markets in transition countries, (5) the future of labor, (6) evaluation of labor market policies and projects and (7) general labor economics.

IZA Discussion Papers often represent preliminary work and are circulated to encourage discussion. Citation of such a paper should account for its provisional character. A revised version may be available on the IZA website (www.iza.org) or directly from the author. 
IZA Discussion Paper No. 924

November 2003

\section{ABSTRACT \\ Employment Effects of Dispersal Policies on Refugee Immigrants, Part I: Theory}

This paper formulates a partial search model in which unemployed individuals simultaneously search for job and location of residence. Most importantly, we show that, ceteris paribus, a decrease in current place utility increases the transition rate into a new location of residence and the transition rate into employment outside the local labour market, but decreases the transition rate into local employment. Thus, a decrease in current place utility decreases the overall job-finding rate if the local reservation wage effect dominates. We argue that dispersal policies on refugee immigrants are characterized by low average values of current place utility. Hence, the model predicts that dispersal policies increase the geographical mobility rates of refugees and, for a sufficiently large local reservation wage effect, decrease their jobfinding rates.

JEL Classification: J64, J68, J15

Keywords: job search, residential search, geographical mobility, dispersal policy on refugees

Corresponding author:

Michael Rosholm

Department of Economics

University of Aarhus

Building 326

8000 Aarhus C

Denmark

Tel.: +45 89421559

Fax: +45861363 34

Email: mrosholm@econ.au.dk 


\section{Introduction}

In this paper, we formulate a partial search model to investigate how dispersal policies for refugee immigrants may affect their labour market integration. Dispersal policies on refugee immigrants are carried out in the US, Germany, the Netherlands, UK, Norway, Denmark and to some extent also in Sweden. Under the dispersal policies, new refugee immigrants are located away from immigrant-dense areas. The main justification for carrying out such dispersal policies is that residential concentration and segregation of immigrants are commonly believed to hamper the integration process of immigrants by slowing down the acquisition of country-specific human capital, such as language skills and knowledge about the host country. Hence, this argument rests on the abundant evidence of slow labour market integration of refugee immigrants. This issue has not been studied extensively, neither from a theoretical nor from an empirical perspective. The purpose of these two companion papers is to perform such an investigation theoretically as well as empirically.

Some empirical evidence exists on relocation effects of settlement policies, see for example Djuve and Kavli (2000), Åslund (2001), Hummelgaard et al. (1995) and Damm (2003) for relocation effects for Norway, Sweden and Denmark, respectively. These studies show very high relocation rates out of small municipalities toward the larger towns and cities during the first two-three years after the initial settlement. ${ }^{1}$

However, as hinted at above, little empirical evidence exists on the labour market effects of settlement policies for the individuals subjected to the poli-

\footnotetext{
${ }^{1} 36 \%$ of the 20,000 refugee immigrants who were located away from immigrant-dense areas in Norway during 1994-1996 had moved away from the municipality of assignment at the end of 1999. The general relocation pattern was that the further away from the metropolitan area in South Norway a refugee immigrant had been placed, the higher the probability of leaving the region. As much as $57 \%$ of the refugee immigrants located in the Northern part of Norway left the region. The main part of the movers moved to towns or cities (Djuve and Kavli 2000).

Aslund (2001) finds that $37.6 \%$ of the refugee immigrants who were located according to the Whole of Sweden Strategy during 1987-1989 had relocated to another municipality within four years after the initial settlement. In addition, he finds that refugees tend to leave small municipalities and are attracted to large municipalities.

In line with the relocation pattern found for refugee immigrants subjected to a settlement policy in Norway or Sweden, Damm (2003) finds that 35\% of 49,000 refugee immigrants placed from 1986-1998 relocated to another municipality after 2-3 years. For refugee immigrants placed in small municipalities, the relocation rate was as high as $54 \%$.
} 
cies. The study by Edin et al. (2001) on labour market effects of 'the Whole of Sweden' settlement policy is to our knowledge the only study addressing this crucial issue, which is really the criterion on which the success of dispersal policies should be judged. They find evidence that refugee immigrants dispersed according to the Whole of Sweden Strategy experienced long-run losses (measured in terms of earnings, idleness and welfare receipt) due to the dispersal policy. They also stress, however, that the secondary migration pattern actually lowers the potential long-run losses due to the policy because of the tendency for refugees to migrate out of areas where their employment prospects are bad. Specifically, their estimates suggest that the probability of being idle would have been 20 percentage points higher if refugees had stayed in the assigned municipalities rather than moved away.

In this paper, we address the issue of labour market effects and residential mobility effects of dispersal policies theoretically. Specifically, we investigate two important questions. First, we investigate how dispersal policies affect subsequent internal geographical mobility rates of refugee immigrants. Second, we look into the impacts of dispersal policies on refugee immigrants' job finding rates. Is it, for example, optimal for individuals located in less immigrant-dense areas to reject job offers until they have relocated into an immigrant-dense area?

When investigating these issues, it is important to note that job and residential search are mutually dependent activities, because both wages and the utility of living in a given location enter into an individual's utility function. Hence, both reservation values are likely to be affected by changes in the model parameters and, moreover, by the place utility offered by the initial location. In consequence, labour and residential mobility should be analysed simultaneously, even if one only wants to answer questions regarding the impact of dispersal policies on labour market integration.

A closely related literature exists, which explains job and residential moving behaviour for unemployed and employed workers in general. As noted by Van Ommeren et al. (2000), many of these studies rely on a sequential ordering of the decision to change residence or job. So individuals search either for jobs given their residence or for a new residence given their job. Examples of the former models include Sugden (1980), Simpson (1980), Van Ophem (1991), Van den Berg (1992), Rouwendal and Rietveld (1994) and Molho (2001). The latter models include Weinberg (1979), Weinberg et al. (1981), Smith and Clark (1982), Clark and Flowerdew (1982) and Pickles and Davies (1991). However, a theory which does not rely on such sequential 
ordering of the decision to change job or residence is better for understanding the interaction between the two decisions. Some models of this kind do exist. Most of them are static equilibrium models in which unexpected shocks and life-cycle changes play a key role, e.g. Weinberg (1979), Linneman and Graves (1983), Zax and Kain (1991) and Zax (1991). However, the existence of large once-only costs of moving implies that individuals are likely to exhibit forward-looking behaviour which is captured by dynamic theories such as search models. The simultaneous search model by Van Ommeren et al. $(1997,2000)$ has both of these attractive features.

The point of departure of the Van Ommeren et al. (1997, 2000) model is that individuals maximise life-time utility by moving through different labour market and residential location states, while taking into consideration that moving from one state to another is costly. Optimal strategies are derived both for employed and non-employed individuals giving rise to four reservation value strategies, for job moves/acceptance and residential relocation for employed and unemployed individuals, respectively. One of their main conclusions based on the search model is that the reservation wages for employed and non-employed depend on labour market characteristics as well as housing market characteristics. That is also the case for the reservation place utility. According to their model, job and residential mobility of non-employed persons are described by transition rates which are the product of offer arrival rates and the conditional probabilities of accepting an offer. Comparative static results for non-employed individuals show that the higher the current place utility, the higher are the reservation wage and reservation place utility. The interpretation of the first result is that individuals with high current place utility are more attached to their present location of residence and therefore less willing to accept a job which induces a residential move. The interpretation of the second result is straightforward, that the higher your current place utility is, the better a residence offer must be for you to accept it. In consequence, the model by Van Ommeren et al. (1997, 2000) predicts that the job-finding rate and housing mobility rate of non-employed individuals are both decreasing in current place utility.

The model by Van Ommeren et al. (1997, 2000) constitutes a good description of the interaction between job and residential mobility for native born individuals. New immigrants, however, may initially differ from individuals in the workforce by lack of information necessary for conducting e.g. job search outside a defined local labour market. Furthermore, dispersal policies aim at labour market integration of refugee immigrants within the region of 
assignment. For these two reasons, the distinction between the local labour market and the national labour market is important for analysis of employment effects of dispersal policies on refugee immigrants. The model by Van Ommeren et al. (1997, 2000) does not distinguish between local and national job search. The optimal search strategies for refugee immigrants may therefore be different from those described in Van Ommeren et al. (1997, 2000). To fill this theoretical gap, we formulate a simultaneous job and residence search model for refugee immigrants who are initially subject to a dispersal policy.

In our model new refugee immigrants begin searching for a job and a new residence simultaneously at the time at which they are granted asylum. First, individuals can search for new residential location instead of the location of assignment by the authorities. Second, they may search for a job locally, i.e. within commuting distance of the present residential location, and finally they may search for employment nationally, i.e. outside the local labour market. As a result of the distinction between local and national job search, commuting distance is taken into account implicitly in our model rather than explicitly as in Van Ommeren et al. (1997, 2000). Hence, we are able to set up a relatively simple model without loosing any important insights into optimal search behaviour of non-employed individuals.

Our main findings are as follows. First, the optimal search strategies are reservation strategies. Reservation wage and reservation place utility values exist at which the individual is indifferent between offer acceptance and rejection, while it is optimal for the individual to accept wage and residence offers if the value of the offer exceeds the reservation value. Hence, the optimal search behaviour of an individual is described by transition rates given as the product of the offer arrival rate and the probability of offer acceptance. Second, the reservation wage for jobs in the local labour market is lower than for a job with similar place utility in another labour market, because the latter involves costs of residential mobility. Third, comparative static results include the following results. The reservation place utility is increasing in the current place utility. In consequence, the transition rate of a non-employed individual into a new region is decreasing in the current place utility. The reservation wage for a national job is increasing in current place utility. The implication is that the transition rate of a non-employed individual into a job which requires a residential move is decreasing in current place utility. In contrast, the reservation wage for a local job is decreasing in the current place utility and, as a consequence, the transition rate 
into a local job is increasing in current place utility. A marginal change in current place utility on the overall transition rate from non-employment to employment, given by the sum of the transition rates into local and national jobs, therefore has an ambiguous effect. However, we argue that, in the case of the Danish labour market (and most Western European labour markets, too), the transition rate into employment is likely to be increasing in current place utility. Finally, we argue that on average a dispersal policy on refugee immigrants is likely to imply a low value of the current place utility. If so, our model predicts that dispersal policy on refugee immigrants is likely to lead to high transition rates of non-employed persons into new regions of residence, low transition rates into local employment and high transition rates into employment outside the local labour market.

The outline of the paper is as follows. The search framework of our basic theoretical model is described informally in the next section. The basic twodimensional search model is described and formally set up in Section 3. The optimal strategies are derived in Section 4. Section 5 presents comparative statics results and their implications for dispersal policies are illustrated in Section 6. Finally, Section 7 concludes.

\section{The search framework}

In this section, we will informally present a dynamic theoretical framework which describes the job and residential location search behaviour of refugee immigrants from the time they are granted asylum until they find their first job in the host country. In contrast to Van Ommeren et al. (1997, 2000), commuting distance is not modelled explicitly but instead implicitly by the distinction between local and national job search. The relationship between job and residential location search behaviour will be described from a searchtheoretical perspective.

The point of departure is that individuals face a set of alternative residential locations and a set of alternative employment opportunities. The individual examines the costs and benefits of any residential location or job offer. These costs and benefits are a function of many characteristics such as personal and household characteristics, current income and residential location characteristics. The individual maximises utility by moving through different residential location states and by changing labour market state, while taking into account once-only costs associated with changing residential lo- 
cation. However, we ignore search costs. We assume that an individual is continuously engaged in search for a better residential location and in search for a job. The rates at which a job or a residence is offered, the so-called job and housing offer arrival rates, are determined by macro factors like job availability and housing supply, but also by characteristics of the individual. The job and housing offer arrival rates are assumed to be exogenous.

As a national job is a job situated outside the local labour market (i.e. outside feasible commuting distance) by assumption, the individual will have to move in order to accept such a job offer. In order to avoid further specificational complexities, we assume that a job offer in the national labour market carries with it a residential offer, that is, it is a draw from a bivariate distribution of jobs and residential offers.

In the job search literature, jobs are characterised by wages and workers are assumed to prefer higher wages (see the overview paper by Devine and Kiefer 1993). In the residential mobility literature, individuals are assumed to prefer a higher place utility to a lower place utility, where place utility is defined as the utility experienced in a certain location net of housing costs, which depend on the specific benefits of the residential location (see Wolpert 1965, Yapa et al. 1971). ${ }^{2}$ We extend these standard assumptions by letting jobs be characterised by wages as well as by their geographical location relative to the current residential location: within commuting distance or not.

\section{Job and residence search: The model}

The two-dimensional search model for refugee immigrants' search for job and residence is presented formally in this section. The model is formulated in continuous time. The point of departure is that a refugee immigrant is granted asylum and settled in a specific residential location away from immigrant-dense areas by the authorities. The individual now searches continuously for a better residential location and simultaneously searches locally and nationally for a job while receiving social assistance (SA) benefits. ${ }^{3}$

\footnotetext{
${ }^{2}$ The concept of 'place utility' was developed by Wolpert who defined it as "a positive or negative quantity, expressing respectively the individual's satisfaction or dissatisfaction with respect to that place" (Wolpert 1965, 162).

${ }^{3}$ One might also consider a simpler model in which individuals can not receive social assistance if they decide to move, a situation corresponding to the three-year 'integration
} 
Individuals derive utility from income $y$ and place utility $r$. The income is SA benefits $b$ while non-employed, and the wage $w$ while employed. The instantaneous utility $u$ experienced by an individual is assumed to be a linear function of $y$ and $r$,

$$
u(y, r)=y+a r
$$

The instantaneous utility is increasing in income and place utility, the marginal utility of income is constant over residential locations and the marginal place utility is constant over income levels. The cross-derivatives are assumed to be zero because we want to focus on the 'pure' dependencies between the reservation strategies and not on dependencies arising from interaction terms in the utility function. The individual faces once-only costs, $c$, of changing residence.

From the individual's point of view of, the economy consists of two labour markets, the local labour market which contains all jobs within commuting distance from the current location of residence, and the national labour market which contains all jobs in the rest of the country. We assume that job offers in both regions arrive according to a Poisson process with arrival rate $\alpha_{1}$ in the local labour market and $\alpha_{2}$ in the national labour market. Thus, in the real world $\alpha_{1}$ will typically be much larger than $\alpha_{2}$, see e.g. the study by Munch et al. (2003). Note that a job offer in the national labour market carries with it a residential location offer, because an individual cannot work outside the local labour market without changing residence. Furthermore, individuals receive residence offers from outside the local labour market (with no associated job offers) which arrive according to a Poisson process with arrival rate $\beta$. The parallellity of these processes is described in Figure 1.

When a job offer is accepted, the individual is assumed to keep the job forever, i.e. no quits or layoffs occur and on-the-job search is ignored as well. Job offers, therefore, stop arriving once a job offer is accepted. Moreover, once a job is accepted, the individual also stops searching for a new residence and thus settles down forever. We assume further that recall of offers is not allowed.

A residence offer is entirely characterised by the place utility $r$ and place

period' prevailing in Denmark since 1999. One might also consider formulating the full model with a three-year 'mobility restraint'. However, this model is non-stationary, and two-dimensional non-stationary search theory is complex. Hence, for the moment, we will abstract from such considerations and look at a stationary environment. 
Figure 1: Description of simultaneous search processes

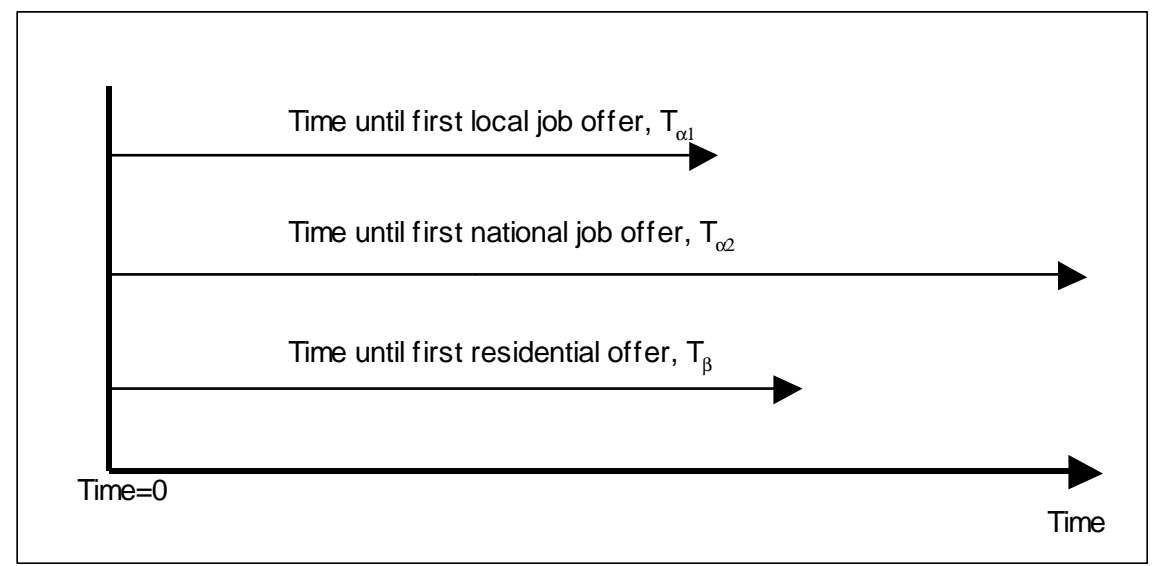

utility offers are random draws from a marginal distribution with CDF $F_{r}(r)$. A job is characterised by the wage $w$ and by its location. Local job offers are random draws from the distribution with $\mathrm{CDF} F_{w}(w)$. National job offers are random draws from the joint wage and place utility distribution $F_{w, r}(w, r)$. We assume that $w$ and $r$ can take only non-negative values. The suprema of $w$ and $r$ are denoted as $\bar{w}$ and $\bar{r}$, respectively. Moreover, for simplicity we assume that $f_{w, r}(w, r)=f_{w}(w) f_{r}(r)$. Finally, the future is discounted at rate $\rho$.

Note that the model is stationary. The value of being unemployed is the discounted expected lifetime utility derived from income flows (wages or SA benefits) and current place utilities, denoted by the value function $V\left(r_{0}\right)$, where $r_{0}$ denotes the place utility at the initial (exogenous) location. Note that under the assumption of random initial location, which is basically what the dispersal policy conducted in Denmark aspires at, ${ }^{4}$ the initial place utility is a random draw from $F_{r}(r)$. The flow value of being non-employed with initial place utility $r_{0}$ is ${ }^{5}$

\footnotetext{
${ }^{4}$ Damm and Rosholm (2003) show that these aspirations are basically met, as the initial distribution of refugee immigrants almost mirrors that of the native Danes.

${ }^{5}$ See the Appendix for the derivation of this equation.
} 


$$
\begin{aligned}
\rho V\left(r_{0}\right)= & b+a r_{0}+\alpha_{1} E_{w} \max \left[0, W\left(w, r_{0}\right)-V\left(r_{0}\right)\right] \\
& +\alpha_{2} E_{w, r} \max \left[0, W(w, r)-c-V\left(r_{0}\right)\right] \\
& +\beta E_{r} \max \left[0, V(r)-c-V\left(r_{0}\right)\right] .
\end{aligned}
$$

where the expectation operator takes expectations with respect to the distribution of the subscripted variable.

The interpretation of the asset equation 2 is as follows. The flow value of being non-nemployed is equal to the sum of four components:

1. The instantaneous utility of the current income and residence.

2. The expected surplus of a local job offer times the rate at which local job offers arrive. This is also denoted the option value of local job search.

3. The expected surplus of a national job (and residential) offer times the rate at which national job offers occur. Denote this the option value of national job search.

4. The expected surplus of a residential offer times the rate at which residence offers arrive. Denote this the option value of residential search.

The flow value of being non-employed can be shown to be increasing in the current place utility. ${ }^{6}$ The intuition is that the higher the current place utility, the higher is the instantaneous place utility and the option value of local job search.

The value of being employed, $W(w, r)$, in a job offering wage $w$ and place utility $r$ is equal to the discounted value of the instantaneous utility of receiving wage $w$ and place utility $r$ forever,

$$
W(w, r)=\frac{w+a r}{\rho}
$$

since we have assumed that once accepted, a job is kept forever and that an individual therefore stops searching for a new residential location, once he has accepted a job. Obviously, the value of being employed is increasing in the wage offered in the accepted job.

With these specifications of the value functions, we can proceed to characterize the optimal strategies of non-employed refugee immigrants.

\footnotetext{
${ }^{6}$ See the Appendix for the derivation of $\frac{\partial V\left(r_{0}\right)}{\partial r_{0}}$.
} 


\section{Optimal strategies}

In this section, we first derive the optimal strategies when receiving a job or residence offer.

The assumptions that $b<\bar{w}$, that the instantaneous utility function is linear in its arguments and that $\alpha_{1}, \alpha_{2}, \beta, \rho>0$ ensure the existence of reservation values $w^{*}\left(r_{0}\right),\left\{R_{w \mid r}\left(r_{0}\right)\right\}$ and $r^{*}\left(r_{0}\right) . w^{*}\left(r_{0}\right)$ is the reservation wage for local jobs, and $\left\{R_{w \mid r}\left(r_{0}\right)\right\}$ is a set of reservation wages for jobs outside the commuting area. These are conditional on the current place utility, $r_{0}$, but also on the place utility associated with the job offer, that is, there is a distribution of reservation wages over associated place utilities. Finally, $r^{*}\left(r_{0}\right)$ is the reservation place utility for residence offers. In the rest of the paper, the dependence of the reservation values on current reservation place utility is suppressed for notational simplicity. ${ }^{7}$

The decision rules for an unemployed individual are then simply the reservation strategies described below:

- Given a local job offer of wage $w$ and given the current place utility $r_{0}$, it is optimal to accept the local job offer if $w>w^{*}$, i.e. the wage level at which an unemployed individual is indifferent between taking the job and remaining unemployed.

- Given a national job offer of wage $w$ and place utility $r$, and given the current place utility $r_{0}$ it is optimal for an unemployed individual to accept the national job offer if $w>R_{w \mid r}$.

- Given a residential offer of $r$ and given the current place utility of $r_{0}$, it is optimal for an unemployed individual to accept the residential offer if $r>r^{*}$.

These reservation strategies imply that job and residential mobility of non-employed persons are described by transition rates which are the product of the offer arrival rate and the probability of accepting an offer (conditional on receiving one).

Let $h_{u}^{l}$ denote the transition rate into a local job. It is given by the product of the local job offer arrival rate and the probability of accepting an offer

\footnotetext{
${ }^{7}$ See the Appendix for the proof of existence of reservation values strategies.
} 


$$
h_{u}^{l}=\alpha_{1}\left[1-F_{w}\left(w^{*}\right)\right]
$$

Similarly, let $h_{u}^{n}$ denote the transition rate into a national job. It is given analogously, by the product of the national job offer arrival rate and the probability of accepting an offer

$$
h_{u}^{n}=\alpha_{2}\left[1-F_{w}\left(R_{w \mid r}\right)\right]
$$

The transition rate out of non-nemployment into employment, $h_{u}$, is the sum of the local job finding rate and the national job finding rate

$$
h_{u}=h_{u}^{l}+h_{u}^{n}
$$

Finally, the transition rate into a new region of a still non-employed person, denoted $h_{r}$, is given by the product of the residence offer arrival rate and the probability of offer acceptance

$$
h_{r}=\beta\left[1-F_{r}\left(r^{*}\right)\right]
$$

Exploiting the reservation value properties, elaborating further on the value function equations using integration by parts allows us to rewrite the asset equation as

$$
\begin{aligned}
\rho V\left(r_{0}\right)= & b+a r_{0}+\frac{\alpha_{1}}{\rho} \int_{w^{*}}^{\bar{w}}\left[1-F_{w}(w)\right] d w \\
& +\frac{\alpha_{2}}{\rho} \int_{0}^{\bar{r}} \int_{R_{w \mid r}}^{\bar{w}}\left[1-F_{w}(w)\right] d w d F_{r}(r) \\
& +\beta \int_{r^{*}}^{\bar{r}} \partial V(r) / \partial r \cdot\left[1-F_{r}(r)\right] d r
\end{aligned}
$$

Being employed at the reservation wage in the local labour market yields flow value

$$
\rho W\left(w^{*}, r_{0}\right)=w^{*}+a r_{0}
$$

At this reservation wage, the non-employed individual is indifferent between continuing search and accepting the offered job, i.e. $W\left(w^{*}, r_{0}\right)=V\left(r_{0}\right)$. These equations above imply that the reservation wage for local jobs is given by 


$$
w^{*}=\varrho V\left(r_{0}\right)-a r_{0}
$$

The reservation wage for a national job in a location offering the same place utility as the current is - by the same line of argument - given by

$$
R_{w \mid r_{0}}=\varrho V\left(r_{0}\right)+\varrho c-a r_{0}
$$

Therefore, we get the result that

$$
R_{w \mid r_{0}}-w^{*}=\varrho c>0
$$

This result is quite intuitive: The reservation wage for a job which requires a residential move to a location offering the exact same place utility as the current place utility exceeds the reservation wage for local jobs by the flow value of the once-only costs of moving, $\varrho c$.

If instead you receive a national job offer in a location offering place utility $r \neq r_{0}$

$$
R_{w \mid r}=\varrho V\left(r_{0}\right)+\varrho c-a r
$$

Therefore,

$$
R_{w \mid r}-R_{w \mid r_{0}}=a\left(r_{0}-r\right)
$$

This expression is obviously positive for $r<r_{0}$ and negative otherwise. So the reservation wage for national job offers is negatively related to the associated place utility. This may seem counterintuitive at first, but follows straightforwardly from a result derived below, stating that the reservation wage for local jobs is negatively related to the current place utility. The intuition of the result will be outlined below.

Furthermore,

$$
R_{w \mid r}-w^{*}=a\left(r_{0}-r\right)+\varrho c
$$

which is unambigously positive for $r<r_{0}+\frac{\rho c}{a}$, and negative otherwise.

\section{Comparative statics}

We now present some comparative statics results many of which are useful for the analysis of the implications of dispersal policies. Formal proofs of the 
following comparative statics propositions are given in the Appendix.

Proposition 1. $r^{*}$ is increasing in $r_{0}$.

The proposition states that the reservation place utility is increasing in the current place utility. The result follows from the definition of the reservation place utility and the fact that the value of being non-employed is increasing in the current place utility. The intuition is straightforward. The higher current place utility, the better must a residence offer be for an individual to accept it. Thus, living in a location which offers a low place utility implies a low reservation place utility and consequently a high transition rate into a new region of residence, $h_{r}$.

COROllary. The reservation place utility exceeds the current place utility.

The reason is that an individual has to be compensated for the once-only costs of moving.

Proposition 2. $R_{w \mid r}$ is increasing in $r_{0}$, while $w^{*}$ is decreasing in $r_{0}$.

This proposition states that the reservation wage for a job outside the local labour market is increasing in current place utility while the reservation wage for a local job is decreasing in the current place utility. Thus, living in a place which offers a low place utility implies a low reservation wage for jobs involving a residential move and consequently a high transition rate into such jobs, $h_{u}^{n}$. The intuition for the result is that the lower current place utility, the less attached is an individual to his current residential location, and consequently, for a given place utility offer $r$, the lower will the wage offers from outside the local labour market have to be to attract him the job.

Turning to the second result, an increase in the current place utility decreases the reservation wage for local jobs, because the option value of receiving a national job offer and of receiving a residential offer both decline. Thus, living in a place which yields low place utility implies that an individual must be 'compensated' for the low place utility by a high wage. Therefore, the individual will set a high reservation wage in the local job market and consequently have a low local job finding rate, $h_{u}^{l}$. A better local wage offer is needed to compensate the individual for the foregone option value from national job search and residential search. 
Proposition 3.

$$
\begin{aligned}
\frac{\partial h_{u}}{\partial r_{0}} & >0 \text { iff } \\
\frac{\alpha_{1} f_{w}\left(w^{*}\right)}{1+\frac{\alpha_{1}}{\rho}\left[1-F_{w}\left(w^{*}\right)\right]} & >\frac{\alpha_{2} f_{w}\left(R_{w \mid r}\right)}{\frac{\alpha_{2}}{\rho} \int_{0}^{\bar{r}}\left[1-F_{w}\left(R_{w \mid r}\right)\right] d F_{r}(r)+\frac{\beta}{\rho}\left[1-F_{r}\left(r^{*}\right)\right]}
\end{aligned}
$$

The proposition states that the transition rate into employment is increasing in current place utility, if the increase in the transition rate into local jobs, resulting from the decline in the local job reservation wage, $w^{*}$, exceeds the decline in the transition rate into jobs outside the local labour market, resulting from the increase in the national job reservation wage, $R_{w \mid r}$. In the case of the Danish labour market, this derivative is likely to be positive, as the transition rate into local jobs is close to 100 times larger than the transition rate into jobs outside the local labour market. Hence, we would expect the impact on the local job reservation wage to dominate.

Looking at another parameter which is of importance for dispersal policies, namely the arrival rate of local job offers, we find the following results.

Proposition 4. $w^{*}$ is increasing in $\alpha_{1}$ and $R_{w \mid r}$ is increasing in $\alpha_{1}$.

The proposition states that the reservation wage for local jobs and the reservation wage for national jobs are increasing in the local job offer arrival rate. This is a standard result, and it simply reflects that with more job offers, searching agents will become more picky.

Similarly, it is an equally well-known result that if the wage offer distribution is log-concave, the increase in the local job offer arrival rate leads to an increase in the transition rate into jobs in the local labour market (the direct effect of an increase in the offer arrival rate dominates the effect of the increase in the reservation wage). However, the transition rate into jobs in the national labour market unambiguously declines. The overall impact on the transition rate from non-employment to employment then depends on the relative size of the two effects. Once again, given the relative sizes of these two hazard rates in most countries, our maintained hypothesis will be that the overall job finding rate is increasing in the local job offer arrival rate.

Comparative static results for $\alpha_{2}$ are derived analogously to the results for $\alpha_{1}$. The results are as follows. 
Proposition 5. $w^{*}$ is increasing in $\alpha_{2}$ and $R_{w \mid r}$ is increasing in $\alpha_{2}$.

The proposition states that the reservation wage for local jobs and the reservation wage for national jobs are increasing in the national job offer arrival rate. Again this result reflects that with more job offers, non-employed agents will become more picky. The transition rate into local jobs unambiguously decreases. The transition rate into jobs in the national labour market will increase, given that the wage offer distribution is log-concave, because then the direct effect of an increase in the offer arrival rate dominates the effect of the increase in the reservation wage. However, given the relative sizes of these two hazard rates in most countries, one could easily find that the overall job finding rate decreases if the national job offer arrival rate increases. In any event, $\alpha_{2}$ is - as we have already mentioned a couple of times - small relative to $\alpha_{1}$, and so any effect of its change is likely to be fairly small, too.

An increase in the local job offer arrival rate has an ambiguous effect on the reservation place utility. Proposition 6 states that an increase in the local job offer arrival rate will lead to an increase in the reservation place utility if the following condition is met.

Proposition 6.

$$
\begin{aligned}
\frac{\partial r^{*}}{\partial \alpha_{1}}> & 0 \text { iff } \\
0< & -\int_{w^{*}\left(r^{*}\right)}^{w^{*}\left(r_{0}\right)}\left[1-F_{w}(w)\right] d w \\
& -\alpha_{1} \frac{\partial w^{*}}{\partial \alpha_{1}}\left(\left[1-F_{w}\left(w^{*}\left(r_{0}\right)\right)\right]-\left[1-F_{w}\left(w^{*}\left(r^{*}\right)\right)\right]\right) \\
& +\alpha_{2} \frac{\partial R_{w \mid r}}{\partial \alpha_{1}} \int_{0}^{\bar{r}}\left(\left[1-F_{w}\left(R_{w \mid r}\left(r^{*}\right)\right)\right]-\left[1-F_{w}\left(R_{w \mid r}\left(r_{0}\right)\right)\right]\right) d F_{r}(r)
\end{aligned}
$$

To interpret the condition, note the following. The first two terms in the inequality capture the total effect of a change in local job offer arrival rate on the change in the option value of local job search due to a change in current place utility from $r_{0}$ to $r^{*}$. The first term is negative, while the latter is positive. Hence, the sign of the total effect on the change in option value of local job search is ambiguous. The third, and last, term in the inequality 
captures the effect of a change in local job offer arrival rate on the change in option value from national job search due to a change in current place utility from $r_{0}$ to $r^{*}$. The term is negative. Therefore, for the reservation place utility to be increasing in the local job offer arrival rate, the second term in the inequality has to be large enough to more than compensate for the two negative terms. Therefore, the interpretation of the condition is that the reservation place utility is increasing in the local job offer arrival rate, if a higher local offer arrival rate means a larger option value of local job search that exceeds the loss in option value from national job search. If so, the individual becomes less inclined to move when the local job offer arrival rate increases.

Similarly, an increase in the national job offer arrival rate has an ambiguous effect on the reservation place utility.

Proposition 7.

$$
\begin{aligned}
\frac{\partial r^{*}}{\partial \alpha_{2}}> & 0 \text { if } \\
0< & -\alpha_{1} \frac{\partial w^{*}}{\partial \alpha_{2}}\left(\left[1-F_{w}\left(w^{*}\left(r_{0}\right)\right)\right]-\left[1-F_{w}\left(w^{*}\left(r^{*}\right)\right)\right]\right) \\
& +\int_{0}^{\bar{r}} \int_{R_{w \mid r}\left(r_{0}\right)}^{R_{w \mid r}\left(r^{*}\right)}\left[1-F_{w}(w)\right] d w d F_{r}(r) \\
& +\alpha_{2} \frac{\partial R_{w \mid r}}{\partial \alpha_{2}} \int_{0}^{\bar{r}}\left(\left[1-F_{w}\left(R_{w \mid r}\left(r^{*}\right)\right)\right]-\left[1-F_{w}\left(R_{w \mid r}\left(r_{0}\right)\right)\right]\right) d F_{r}(r)
\end{aligned}
$$

The interpretation of the proposition is that the reservation place utility is increasing in the national job offer arrival rate, if the potential loss in the option value from national job search due to a higher national job offer arrival rate (the net effect of the two latter terms in the inequality) is more than compensated by the gain in the option value from local job search due to a higher national job offer arrival rate (the first term in the inequality). 


\section{Model implications of dispersal policy on new refugees}

We can use some of these comparative statics results to analyse the implications of a dispersal policy for new refugees. Dispersal policy is likely to imply low average values of the current place utility, $r_{0}$, e.g. due to lack of an ethnic or immigrant network and lack of own influence on the choice of location. Since refugee immigrants are not free to choose where to live (that is exactly the implication of a dispersal policy), some of them will find themselves in locations to which they attribute very low place utility. Proposition 1 then implies that, a priori, dispersal policies are likely to lead to lower reservation place utilities and consequently higher relocation rates. The high subsequent migration rates of refugees who had initially been subject to dispersal policy found in empirical studies for the US, Sweden, Norway and Denmark are supportive evidence in favour of this hypothesis.

Moreover, Proposition 2 then implies that, a priori, dispersal policies low average values of current place utility - are expected to lead to lower transition rates into local employment due to higher local reservation wages and to higher transition into employment outside the local labour market due to lower reservation wages in the national labour market. Hence, dispersal policies have the likely implication that a better local wage offer is needed for local job acceptance to compensate the individual for the foregone option value from national job search and residential search.

Furthermore, the implication of Proposition 3 is that theoretically the effect of dispersal policies on the job finding rate is ambiguous. However, empirically the effect is likely to be negative, at least for most European labour markets, which are characterised by a transition rate into local jobs close to 100 times larger than the transition rates into jobs outside the local labour market. Hence, we would expect the impact on the local job reservation wage to dominate.

This may explain the empirical finding in Damm and Rosholm (2003) that refugee immigrants who live in areas with a large concentration of country fellowmen find a job faster. This finding may thus not necessarily have anything to do with the access to a larger social network, but may instead be a consequence of their lower reservation wages! Moreover, upon correcting for endogenous residential mobility, we find in that paper that movers have much larger job finding rates than stayers, even though the observed labour 
market characteristics of the municipalities, to which the refugee immigrants were assigned under the dispersal policy, are more 'favourable' to immigrants' employment outcomes than the municipalities they subsequently move to. This suggests that there are large reservation wage effects, which are caused by location characteristics which we do not observe in the data.

Dispersal policies also imply that the local job offer arrival rate is exogenously given. Another interesting issue is therefore what the optimal behaviour is for an individual who is assigned to a location characterised by a relatively low job offer arrival rate. However, the model is not ideal for theoretical investigation of this issue, because it does not allow for differences in the local job offer arrival rate across regions; if a person moves from one local labour market to another, the job offer arrival rate in the new local labour market stays the same as the job offer arrival rate in the previous local labour market. The local job offer arrival rate relative to the national job offer arrival rate does not capture interregional differences in job offer arrival rates, but differences in job offer arrival rates due to differences in local and national job search methods. Local job search methods may, for instance, result in more job offers than national job search methods due to the network of the individual relaying information about vacant jobs locally rather than nationally or due to lower costs of showing up in person to apply for a job locally rather than nationally. Thus, it would be interesting to extend the model to allow for interregional differences in job offer arrival rates since this feature is necessary for derivation of theoretical labour market implications of assignment to a region with a low job offer arrival rate relatively to other regions. Until then, one may argue that a decrease in the local unemployment rate relative to the local unemployment rate in other regions can be captured in the present model framework by an increase in the current place utility.

\section{Conclusion}

By setting up a simple partial search model in which non-employed agents search continuously for jobs and new residences and deriving the optimal search strategies of agents, we have explored the relationship between current place utility, region-specific offer arrival rates and transition rates into employment and a new region of residence. Knowledge about these relationships is useful for theoretical investigation of labour market and residential 
mobility implications of dispersal policies on refugee immigrants.

Most importantly, our analysis has demonstrated the following. First, the reservation wage for jobs in the local labour market is lower than for a job with similar place utility in another labour market, because the latter involves costs of residential mobility. Second, the reservation place utility is increasing in the current place utility. In consequence, the transition rate of a non-employed individual into a new region is decreasing in the current place utility. Third, the reservation wage for a national job is increasing in current place utility. The implication is that the transition rate of a nonemployed individual into a job which requires a residential move is decreasing in current place utility. In contrast, the reservation wage for a local job is decreasing in the current place utility and, as a consequence, the transition rate into a local job is increasing in current place utility. A marginal change in current place utility on the overall transition rate from non-employment to employment, given by the sum of the transition rates into local and national jobs, therefore has an ambiguous effect.

We argue that a dispersal policy on refugee immigrants is likely on average to imply a low value of the current place utility. If so, our model predicts that dispersal policy on refugee immigrants is likely to lead to high transition rates of non-employed persons into new regions of residence, low transition rates into local employment and high transition rates into national employment. Theoretically, the effect of dispersal policies on the job finding rate is ambiguous. However, we argue that in the case of the Danish labour market the local reservation wage effect is likely to dominate. In consequence, the transition rate into employment is likely to be increasing in current place utility. In consequence, we would expect dispersal policies to have a negative effect on the overall job finding rate of non-employed refugee immigrants who were initially subject to dispersal policy.

The model constructed is obviously quite stylized. Apart from the model extension suggested in Section 6, future research might attempt to incorporate the aspect that over time spent in the host country, immigrants become more employable due to acquisition of host-country-specific human capital such as language. This employability aspect could be incorporated by assuming that the job offer arrival rate is increasing over time since immigration due to increased employability. Alternatively, to avoid nonstationarity full employability could be assumed to arrive according to some stochastic process and the job offer arrival rate could be assumed to be at a low level before attainment of full employability and high afterwards. 
One might also consider the possibility that the place utility immigrants attach to a certain location can change over time, as in a learning model. Thus, the perception of locations which initially may seem unfriendly can change as the refugee gets to know the local population etc. Of course, the opposite may also happen, but the implication of a learning model would be interesting to analyse.

\section{References}

[1] Clark, W.A.W. and R. Flowerdew. 1982. A review of search models and their application to search in the housing market. In: Clark, W.A.W. (ed.) Modelling housing market search, London: Croom Helm.

[2] Damm, A.P. 2003. Immigrants' Location Preferences: Exploiting a Natural Experiment. Chapter 2 in this thesis.

[3] Damm, A.P. and M. Rosholm. 2003. Employment Effects of Dispersal Policies on Refugee Immigrants, Part II: Empirical Evidence. Chapter 4 in this thesis.

[4] Devine, T.J. and M. M. Kiefer. 1993. The Empirical Status of Job Search Theory. Labour Economics 1: 3-24.

[5] Djuve, A. B. and H. C. Kavli. 2000. Styring over eget liv. Levekår pg flytteaktivitet blant flyktinger i lys av myndighetenes bosettingsarbeid. Fafo-rapport 344.

[6] Edin, P.-A., P. Fredriksson and O. Åslund. 2001. Settlement policies and the economic success of immigrants. CEPR Discussion Paper 2730.

[7] Hummelgaard, H., L. Husted, A. Holm, M. Baadsgaard and B. Olrik. 1995. Etniske minoriteter, integration og mobilitet. Copenhagen: AKF.

[8] Linneman, P. and P.E. Graves. 1983. Migration and job change: A multinomial logit approach. Journal of Urban Economics 14: 263-279.

[9] Molho, I. 2001. Spatial Search, Migration and Regional Unemployment. Economica 68: 269-283. 
[10] Munch, J. R., M. Rosholm, and M. Svarer. 2003. Are Home Owners Really More Unemployed? IZA Discussion Paper 872, IZA, Bonn.

[11] Pickles A.R. and R.B. Davies. 1991. The empirical analysis of housing careers: a review and a general statistical modelling framework. Environment and Planning A, 23: 465-484.

[12] Rouwendal, J. and P. Rietveld. 1994. Commuting distance distributions of Dutch households. Urban Studies 31(09): 1545-1557.

[13] Simpson, W. 1980. A simultaneous model of workplace and residential location incorporating job search. Journal of Urban Economics 8: 330349 .

[14] Smith, T.R. and W.A.W. Clark. 1982. Housing market search behaviour and expected mobility, theory 1: measuring preferences for housing. Environment and Planning A, 14: 681-698.

[15] Sugden, R. 1980. An application of search theory to the analysis of regional labour markets. Regional Science and Urban Economics 10: $43-51$.

[16] Van den Berg, G.J. 1992. A structural Dynamic Analysis of job turnover and the costs associated with moving to another job. The Economic Journal 102: 1116-1133.

[17] Van Ommeren, J., P. Rietveld and P. Nijkamp. 1997. Commuting: in search of jobs and residences. Journal of Urban Economics 42: 402-421.

[18] Van Ommeren, J., P. Rietveld and P. Nijkamp. 2000. Job Mobility, Residential Mobility and Commuting: A Theoretical Analysis using Search Theory. The Annals of Regional Science 34: 213-232.

[19] Van Ophem, H.. 1991. Wages, nonwage job characteristics and the search behaviour of employees. The Review of Economics and Statistics 73: 145-151.

[20] Weinberg, D.H. 1979. The determinants of intra-urban household mobility. Regional Science and Urban Economics 9: 219-246. 
[21] Weinberg, D.H., J. Friedman, and S.K. Mayo. 1981. Intraurban residential mobility: the role of transaction costs, market imperfections and household disequilibrium. Journal of Urban Economics 9: 332-348.

[22] Wolpert, G. 1965. Behavioral aspects of the decision to migrate. Papers and Proceedings of the Regional Science Association 15: 159-169.

[23] Yapa, L., M. Polese and J. Wolpert. 1971. Interdependencies of commuting, migration and job site relocations. Economic Geography 47: 59-72.

[24] Zax, J.S. 1991. The substitution between moves and quits. The Economic Journal 101: 1510-1521.

[25] Zax, J.S. and J.F. Kain. 1991. Commutes, quits, and moves. Journal of Urban Economics 29: 153-165.

[26] Åslund, O. 2001. Now and forever? Initial and subsequent location choices of immigrants. IFAU. Working Paper 11. 


\section{Appendix A. 1}

Derivation of Equation (2):

$$
\begin{aligned}
V\left(r_{0}\right) & =E_{T}\left[\int_{0}^{T} u\left(b, r_{0}\right) e^{-\rho t} d t\right] \\
+\operatorname{Pr}\left(T_{\alpha 1}\right. & \left.<\min \left\{T_{\alpha 2}, T_{\beta}\right\}\right) E_{T_{\alpha 1}}\left[e^{-\rho T_{\alpha 1}} \mid T_{\alpha 1}<\min \left\{T_{\alpha 2}, T_{\beta}\right\}\right] E_{w} \max \left[V\left(r_{0}\right), W\left(w, r_{0}\right)\right] \\
+\operatorname{Pr}\left(T_{\alpha 2}\right. & \left.<\min \left\{T_{\alpha 1}, T_{\beta}\right\}\right) E_{T_{\alpha 2}}\left[e^{-\rho T_{\alpha 2}} \mid T_{\alpha 2}<\min \left\{T_{\alpha 1}, T_{\beta}\right\}\right] E_{w r} \max \left[V\left(r_{0}\right), W(w, r)-c\right] \\
+\operatorname{Pr}\left(T_{\beta}\right. & \left.<\min \left\{T_{\alpha 1}, T_{\alpha 2}\right\}\right) E_{T_{\beta}}\left[e^{-\rho T_{\beta}} \mid T_{\beta}<\min \left\{T_{\alpha 1}, T_{\alpha 2}\right\}\right] E_{r} \max \left[V\left(r_{0}\right), V(r)-c\right]
\end{aligned}
$$

where $T_{\alpha 1}$ denotes time until arrival of the next local job offer, $T_{\alpha 2}$ denotes time until arrival of the next national job offer, $T_{\beta}$ denotes time until arrival of the next residence offer, and finally $T$ denotes the minimum of the three random variables $T_{\alpha 1}, T_{\alpha 2}$ and $T_{\beta}$. Further, $E$ denotes the expectation, i.e. $E_{T}[\cdot]$ is the expected value of the term in the square brackets where the expectation is taken with respect to the variable $T, \rho$ denotes the discount rate and $W(w, r)$ is the value of being employed in a job offering $w$ while living in a location yielding place utility $r$. Since job and residence offers arrive according to Poisson processes with arrival rates $\alpha_{1}, \alpha_{2}$ and $\beta$, respectively, the random variables $T_{\alpha 1}, T_{\alpha 2}$ and $T_{\beta}$ are exponentially distributed with parameters $\alpha_{1}, \alpha_{2}$ and $\beta$, respectively. One can show that this implies that the minimum of the three random variables $T$ is exponentially distributed with the parameter $\alpha_{1}+\alpha_{2}+\beta .^{1}$ The interpretation of the above formula is the following. The value of being unemployed is equal to the sum of four components: First, the expected discounted value of receiving the instantaneous utility of social assistance benefits and the current place utility $r$ from now until the arrival of either a residence or a job offer, second, the expected discounted value of receiving a local job offer times the probability of receiving a local job offer before the arrival of a national job offer or a residence offer, third, the expected discounted value of receiving a national job offer times the probability of receiving a national job offer as the next offer, and finally the expected discounted value of receiving a residence offer times the probability of receiving a residence offer before any job offers.

By calculating the expectiations on the right-hand side of Equation (A-1), we obtain the following expression for the value of being unemployed in a location yielding place utility $r_{0}$

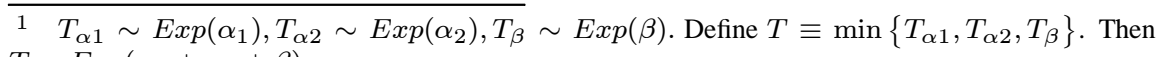
$T \sim \operatorname{Exp}\left(\alpha_{1}+\alpha_{2}+\beta\right)$.

Proof: $\operatorname{Pr}(T<t)=1-\operatorname{Pr}(T>t)=1-\operatorname{Pr}\left(T_{\alpha 1}>t, T_{\alpha 2}>t, T_{\beta}>t\right)=$ $1-\operatorname{Pr}\left(T_{\alpha 1}>t\right) \operatorname{Pr}\left(T_{\alpha 2}>t\right) \operatorname{Pr}\left(T_{\beta}>t\right)=1-e^{-\alpha_{1} t} e^{-\alpha_{2} t} e^{-\beta t}=1-e^{-\left(\alpha_{1}+\alpha_{2}+\beta\right) t}$.
} 


$$
\begin{aligned}
V\left(r_{0}\right)= & \frac{b+a r_{0}}{\alpha_{1}+\alpha_{2}+\beta+\rho}+\frac{\alpha_{1}}{\alpha_{1}+\alpha_{2}+\beta+\rho} E_{w} \max \left[V\left(r_{0}\right), W\left(w, r_{0}\right)\right] \\
& +\frac{\alpha_{2}}{\alpha_{1}+\alpha_{2}+\beta+\rho} E_{w r} \max \left[V\left(r_{0}\right), W(w, r)-c\right] \\
& +\frac{\beta}{\alpha_{1}+\alpha_{2}+\beta+\rho} E_{r} \max \left[V\left(r_{0}\right), V(r)-c\right]
\end{aligned}
$$

Multiplication by the factor $\left(\alpha_{1}+\alpha_{2}+\beta+\rho\right)$ on both sides and subtracting $\left(\alpha_{1}+\alpha_{2}+\beta\right) V\left(r_{0}\right)$ from both sides of Equation (A-2) in order to isolate $\rho V\left(r_{0}\right)$, Equation (A-2) can be rewritten in a more familiar form of a flow value or asset equation,

$$
\begin{aligned}
\rho V\left(r_{0}\right)= & b+a r_{0}+\alpha_{1} E_{w} \max \left[0, W\left(w, r_{0}\right)-V\left(r_{0}\right)\right] \\
& +\alpha_{2} E_{w r} \max \left[0, W(w, r)-c-V\left(r_{0}\right)\right] \\
& +\beta E_{r} \max \left[0, V(r)-c-V\left(r_{0}\right)\right]
\end{aligned}
$$

The first term on the right-hand side of Equation (A-1) is solved for as follows,

$$
\begin{aligned}
& E_{T}\left[\int_{0}^{T} u\left(b, r_{0}\right) e^{-\rho t} d t\right] \\
= & \left(b+a r_{0}\right) E_{T}\left[\left(-\frac{1}{\rho} e^{-\rho t}\right)\right]_{0}^{T} \\
= & \frac{b+a r_{0}}{\rho} E_{T}\left(1-e^{-\rho T}\right) \\
= & \frac{b+a r_{0}}{\rho} \int_{0}^{\infty}\left(1-e^{-\rho T}\right) f(T) d T \\
= & \frac{b+a r_{0}}{\rho} \int_{0}^{\infty}\left(1-e^{-\rho T}\right)\left(\alpha_{1}+\alpha_{2}+\beta\right) e^{-\left(\alpha_{1}+\alpha_{2}+\beta\right) T} d T \\
= & \frac{b+a r_{0}}{\rho} \frac{\rho}{\alpha_{1}+\alpha_{2}+\beta+\rho} \\
= & \frac{b+a r_{0}}{\alpha_{1}+\alpha_{2}+\beta+\rho}
\end{aligned}
$$

Concerning the second term on the right-hand side of Equation (A-1), 


$$
\begin{aligned}
\operatorname{Pr}\left(T_{\alpha_{2}}\right. & \left.<\min \left\{T_{\alpha_{2}}, T_{\beta}\right\}\right) E_{T_{\alpha_{1}}}\left[e^{-\rho T_{\alpha_{1}}} \mid T_{\alpha_{1}}<\min \left\{T_{\alpha_{2}}, T_{\beta}\right\}\right] \\
& =\int_{0}^{\infty} e^{-\rho t} \operatorname{Pr}\left(T_{\alpha_{2}}>t\right) \operatorname{Pr}\left(T_{\beta}>t\right) d F_{T_{\alpha_{1}}}(t) \\
& =\int_{0}^{\infty} e^{-\rho t} e^{-\alpha_{2} t} e^{-\beta t} \alpha_{1} e^{-\alpha_{1} t} d t \\
& =\frac{\alpha_{1}}{\alpha_{1}+\alpha_{2}+\beta+\rho}
\end{aligned}
$$

The third and fourth probability terms on the right-hand side of Equation (A-1) are calculated analogously!

Existence of reservation values:

It is fairly easy to show that a local reservation wage exists for unemployed individuals. Since $W\left(w, r_{0}\right)$ is strictly increasing in $w$ and $V\left(r_{0}\right)$ is constant in $w$, a cut-off wage level $w^{*}$ exists at which $W\left(w^{*}, r_{0}\right)=V\left(r_{0}\right) . w^{*}\left(r_{0}\right)$ is the so-called reservation wage level,

$$
\begin{aligned}
\partial W\left(w, r_{0}\right) / \partial w & =\frac{u_{w}^{\prime}\left(w, r_{0}\right)}{\rho}=\frac{1}{\rho}>0 \text { and } \partial V\left(r_{0}\right) / \partial w=0 \\
& \Rightarrow \exists w^{*}\left(r_{0}\right) \text { s.t. } W\left(w^{*}\left(r_{0}\right), r_{0}\right)=V\left(r_{0}\right)
\end{aligned}
$$

Moreover, note that $\operatorname{Pr}\left(W\left(w, r_{0}\right) \leq V\left(r_{0}\right)\right)=\operatorname{Pr}\left(W\left(w, r_{0}\right) \leq W\left(w^{*}\left(r_{0}\right), r_{0}\right)\right)=$ $\operatorname{Pr}\left(w \leq w^{*}\left(r_{0}\right)\right)=F_{w}\left(w^{*}\left(r_{0}\right)\right)$ since $W\left(w, r_{0}\right)$ is increasing in $w$ and $w^{*}\left(r_{0}\right)$ exists.

Existence of a national reservation wage is shown analogously

$$
\begin{aligned}
\partial W(w, r) / \partial w & =\frac{u_{w}^{\prime}\left(w, r_{0}\right)}{\rho}=\frac{1}{\rho}>0 \text { and } \partial V\left(r_{0}\right) / \partial w=0 \\
& \Rightarrow \forall r \exists R_{w \mid r}\left(r_{0}\right) \text { s.t. } W\left(R_{w \mid r}\left(r_{0}\right), r\right)=V\left(r_{0}\right)+c
\end{aligned}
$$

since $u_{y}^{\prime}\left(y, r_{0}\right)>0 \Rightarrow u_{w}^{\prime}\left(w, r_{0}\right)>0$. Naturally, we also need the additional assumption here that $b<\bar{w}$.

Moreover, note that $\operatorname{Pr}\left(W(w, r)-c \leq V\left(r_{0}\right)\right)=\operatorname{Pr}(W(w, r)-c \leq$ $\left.W\left(R_{w \mid r}\left(r_{0}\right), r_{0}\right)\right)=\operatorname{Pr}\left(w \leq R_{w \mid r}\left(r_{0}\right)\right)=F_{w}\left(R_{w \mid r}\left(r_{0}\right)\right)$ since $W\left(R_{w \mid r}\left(r_{0}\right), r_{0}\right)$ is increasing in $w$ and $R_{w \mid r}\left(r_{0}\right)$ exists.

Similarly, a cut-off place utility level $r^{*}\left(r_{0}\right)$ exists at which $V\left(r^{*}\left(r_{0}\right)\right)-c=V\left(r_{0}\right)$, because $V(r)$ is strictly increasing in $r$ since $u_{r}^{\prime}\left(y, r_{0}\right)>0$ and $u_{y r}^{\prime}\left(w, r_{0}\right)=0$, whereas $V\left(r_{0}\right)$ is constant in $r$,

$$
\partial V(r) / \partial r>0 \text { and } \partial V\left(r_{0}\right) / \partial r=0 \Rightarrow \exists r^{*}\left(r_{0}\right) \text { s.t. } V\left(r^{*}\left(r_{0}\right)\right)=V\left(r_{0}\right)+c
$$

$r^{*}\left(r_{0}\right)$ is called the reservation place utility level.

Moreover, since $V(r)$ is strictly increasing in $\mathrm{r}, \operatorname{Pr}\left(V(r)-c<V\left(r_{0}\right)\right)=\operatorname{Pr}(V(r) \leq$ $\left.V\left(r^{*}\left(r_{0}\right)\right)\right)=\operatorname{Pr}\left(r<r^{*}\left(r_{0}\right)\right) .=F_{r}\left(r^{*}\left(r_{0}\right)\right)$.

Where possible, the dependence of the reservation values on current place utility is suppressed in the rest of the Appendix for notational simplicity. 
That $V(r)$ is strictly increasing in $r$ can be seen from derivation of Equation (A-2) with respect to $r_{0}$ which produces

$$
\begin{aligned}
\frac{\partial V\left(r_{0}\right)}{\partial r_{0}}= & \frac{a}{\alpha_{1}+\alpha_{2}+\beta+\varrho} \\
& +\frac{\alpha_{1}}{\alpha_{1}+\alpha_{2}+\beta+\varrho}\left[\begin{array}{c}
\operatorname{Pr}\left(W\left(w, r_{0}\right) \leq V\left(r_{0}\right)\right) \frac{\partial V\left(r_{0}\right)}{\partial r_{0}} \\
+\operatorname{Pr}\left(W\left(w, r_{0}\right)>V\left(r_{0}\right)\right) \frac{\partial W\left(w, r_{0}\right)}{\partial r_{0}}
\end{array}\right] \\
& +\frac{\alpha_{2}}{\alpha_{1}+\alpha_{2}+\beta+\varrho}\left[\operatorname{Pr}\left(W(w, r)-c \leq V\left(r_{0}\right)\right) \frac{\partial V\left(r_{0}\right)}{\partial r_{0}}\right] \\
& +\frac{\beta}{\alpha_{1}+\alpha_{2}+\beta+\varrho}\left[\operatorname{Pr}\left(V(r)-c \leq V\left(r_{0}\right)\right) \frac{\partial V\left(r_{0}\right)}{\partial r_{0}}\right]
\end{aligned}
$$

Isolation of $\frac{\partial V\left(r_{0}\right)}{\partial r_{0}}$ on the left-hand side produces

$$
\begin{aligned}
& \frac{\partial V\left(r_{0}\right)}{\partial r_{0}}= \\
& \frac{a+\alpha_{1} \operatorname{Pr}\left(W\left(w, r_{0}\right)>V\left(r_{0}\right)\right) \frac{\partial W\left(w, r_{0}\right)}{\partial r_{0}}}{\varrho+\alpha_{1}\left[1-\operatorname{Pr}\left(W\left(w, r_{0}\right) \leq V\left(r_{0}\right)\right]+\alpha_{2}\left[1-\operatorname{Pr}\left(W(w, r)-c \leq V\left(r_{0}\right)\right)\right]+\beta\left[1-\operatorname{Pr}\left(V(r)-c \leq V\left(r_{0}\right)\right)\right]\right.}
\end{aligned}
$$

This expression is positive, since all terms in the numerator and the denominator are positive. Note that in the absence of national job search and residential search $\frac{\partial V\left(r_{0}\right)}{\partial r_{0}}$ would simply be equal to $\frac{a}{\varrho}$.

Exploiting the reservation value properties, we get that

$$
\begin{aligned}
\frac{\partial V\left(r_{0}\right)}{\partial r_{0}} & =\frac{a\left[1+\frac{\alpha_{1}}{\varrho}\left(1-F_{w}\left(w^{*}\right)\right)\right]}{\rho+\alpha_{1}\left(1-F_{w}\left(w^{*}\right)\right)+\alpha_{2} \int_{0}^{\bar{r}}\left[1-F_{w}\left(R_{w \mid r}\right)\right] d F_{r}(r)+\beta\left(1-\operatorname{Pr}\left(V(r)-c \leq V\left(r_{0}\right)\right)\right)} \\
& =\frac{\frac{a}{\rho} \cdot\left[1+\frac{\alpha_{1}}{\varrho}\left(1-F_{w}\left(w^{*}\right)\right)\right]}{1+\frac{\alpha_{1}}{\rho}\left[1-F\left(w^{*}\right)\right]+\frac{\alpha_{2}}{\rho} \int_{0}^{\bar{r}}\left[1-F_{w}\left(R_{w \mid r}\right)\right] d F_{r}(r)+\frac{\beta}{\rho}\left[1-F_{r}\left(r^{*}\right)\right]}>0
\end{aligned}
$$

Hence, $\frac{\partial V\left(r_{0}\right)}{\partial r_{0}}$ is greater than zero since $u_{r_{0}}^{\prime}\left(b, r_{0}\right)>0$ and $\alpha_{1}, \alpha_{2}, \beta, \rho>0$.

Exploiting the reservation value properties, elaborating further on the value function equations using integration by parts produces 


$$
\begin{aligned}
\rho V\left(r_{0}\right)= & b+a r_{0}+\alpha_{1} \int_{w^{*}}^{\bar{w}}\left[W\left(w, r_{0}\right)-V\left(r_{0}\right)\right] d F_{w}(w) \\
& \left.+\alpha_{2} \int_{0}^{\bar{r}} \int_{R_{w \mid r}}^{\bar{w}}\left[W(w, r)-c-V\left(r_{0}\right)\right)\right] d F_{w}(w) d F_{r}(r) \\
& \left.+\beta \int_{r^{*}}^{\bar{r}}\left[V(r)-c-V\left(r_{0}\right)\right)\right] d F_{r}(r) \\
= & b+a r_{0}+\alpha_{1} \int_{w^{*}}^{\bar{w}}\left[W\left(w, r_{0}\right)-W\left(w^{*}, r_{0}\right)\right] d F_{w}(w) \\
& +\alpha_{2} \int_{0}^{\bar{r}} \int_{R_{w \mid r}}^{\bar{w}}\left[W(w, r)-W\left(R_{w \mid r}, r\right)\right] d F_{w}(w) d F_{r}(r) \\
& +\beta \int_{r^{*}}^{\bar{r}}\left[V(r)-V\left(r^{*}\right)\right] d F_{r}(r) \\
= & b+a r_{0}+\frac{\alpha_{1}}{\rho} \int_{w^{*}}^{\bar{w}}\left[1-F_{w}(w)\right] d w \\
& +\frac{\alpha_{2}}{\rho} \int_{0}^{\bar{r}} \int_{R_{w \mid r}}^{\bar{w}}\left[1-F_{w}(w)\right] d w d F_{r}(r) \\
& +\beta \int_{r^{*}}^{\bar{r}} \partial V(r) / \partial r \cdot\left[1-F_{r}(r)\right] d r
\end{aligned}
$$

\section{Comparative statics:}

ProOf OF PROPOSITION 1:

The reservation place utility $r^{*}$ is defined as the place utility for which

$$
V\left(r^{*}\right)=V\left(r_{0}\right)+c
$$

where $V(r)$ is increasing in $r$, see eq. (A-9) above. It follows straightforwardly that

$$
\frac{\partial r^{*}}{\partial r_{0}}>0
$$

PRoOf OF PRoposition 2:

An increase in $r_{0}$ leads to an increase in $R_{w \mid r}$ since

$$
\frac{\partial R_{w \mid r}}{\partial r_{0}}=\frac{\partial\left(\varrho V\left(r_{0}\right)\right)}{\partial r_{0}}>0,
$$

where the positive sign of $\frac{\partial\left(V\left(r_{0}\right)\right)}{\partial r_{0}}$ was derived above.

The derivative of the reservation wage for local jobs with respect to current place utility is given by 


$$
\begin{aligned}
\frac{\partial w^{*}}{\partial r_{0}}= & -\frac{\alpha_{1}}{\rho}\left[1-F\left(w_{1}^{*}\right)\right] \frac{\partial w^{*}}{\partial r_{0}}- \\
& \frac{\alpha_{2}}{\rho} \int_{0}^{\bar{r}}\left[1-F_{w \mid r}\left(R_{w \mid r}\right)\right] \frac{\partial R_{w \mid r}}{\partial r_{0}} d F_{r}(r)+\frac{\partial \Theta\left(r_{0}\right)}{\partial r_{0}} \\
\frac{\partial w^{*}}{\partial r_{0}}= & \frac{1}{1+\frac{\alpha_{1}}{\varrho}\left[1-F\left(w^{*}\right)\right]} \\
& \cdot\left[-\frac{\alpha_{2}}{\rho} \int_{0}^{\bar{r}}\left[1-F_{w}\left(R_{w \mid r}\right)\right] \frac{\partial R_{w \mid r}}{\partial r_{0}} d F_{r}(r)+\beta \frac{\partial \Theta\left(r_{0}\right)}{\partial r_{0}}\right]<0
\end{aligned}
$$

where

$$
\Theta\left(r_{0}\right):=\int_{r^{*}}^{\bar{r}} \partial V(r) / \partial r \cdot\left[1-F_{r}(r)\right] d r
$$

This derivative is negative because the denominator is positive and the numerator unambigously negative, because both terms in the numerator are negative. The second term in the numerator is clearly negative, since the option value of further residential search obviously declines with the current place utility. In the extreme, if you live in the region offering the highest place utility, the option value of further residential search is 0 . The first term in the numerator is negative, because $\frac{\partial R_{w \mid r}}{\partial r_{0}}>0$.

PROOF OF PROPOSITION 3:

The transition rate out of non-nemployment is the sum of the local job finding rate and the national job finding rate

$$
h_{u}=\alpha_{1}\left[1-F_{w}\left(w^{*}\right)\right]+\alpha_{2}\left[1-F_{w}\left(R_{w \mid r}\right)\right]
$$

The derivative of this transition rate from non-employment into employment with respect to current place utility is

$$
\frac{\partial h_{u}}{\partial r_{0}}=\alpha_{1} f_{w}\left(w^{*}\right) a-\left[\alpha_{1} f_{w}\left(w^{*}\right)+\alpha_{2} f_{w}\left(R_{w \mid r}\right)\right] \varrho \frac{\partial\left(V\left(r_{0}\right)\right)}{\partial r_{0}}
$$

Inserting the expression for $\frac{\partial V\left(r_{0}\right)}{\partial r_{0}}$ into the expression for $\frac{\partial h_{u}}{\partial r_{0}}$ and rearranging terms we see that

$$
\frac{\partial h_{u}}{\partial r_{0}}>0 \text { if } \frac{\alpha_{1} f_{w}\left(w^{*}\right)}{1+\frac{\alpha_{1}}{\rho}\left[1-F_{w}\left(w^{*}\right)\right]}>\frac{\alpha_{2} f_{w}\left(R_{w \mid r}\right)}{\frac{\alpha_{2}}{\rho} \int_{0}^{\bar{r}}\left[1-F_{w}\left(R_{w \mid r}\right)\right] d F_{r}(r)+\frac{\beta}{\rho}\left[1-F_{r}\left(r^{*}\right)\right]},
$$

Derivation of $\frac{\partial r^{*}}{\partial \alpha_{1}}$ : Subtracting the value functions evaluated at $r_{0}$ and $r^{*}$ and exploiting the signs of the derivatives of the reservation values wrt. the current place utility, we obtain 


$$
\begin{aligned}
& r^{*}=r_{0}+ \\
& \frac{1}{a}\left\{\begin{array}{c}
-\frac{\alpha_{1}}{\rho} \int_{w^{*}\left(r^{*}\right)}^{w^{*}\left(r_{0}\right)}\left[1-F_{w}(w)\right] d w+\frac{\alpha_{2}}{\rho} \int_{0}^{\bar{r}} \int_{R_{w \mid r}\left(r_{0}\right)}^{R_{w \mid r}\left(r^{*}\right)}\left[1-F_{w}(w)\right] d w d F_{r}(r) \\
+\beta \int_{r^{*}}^{r^{* *}}\left[V(r)-c-V\left(r^{*}\right)\right] F_{r}(r) d r+\beta\left[1-F_{r}\left(r^{*}\right)\right] c+\varrho c
\end{array}\right\} \\
& =r_{0}+ \\
& \frac{1}{a}\left\{\begin{array}{c}
-\frac{\alpha_{1}}{\rho} \int_{w^{*}\left(r^{*}\right)}^{w^{*}\left(r_{0}\right)}\left[1-F_{w}(w)\right] d w+\frac{\alpha_{2}}{\rho} \int_{0}^{\bar{r}} \int_{R_{w \mid r}\left(r_{0}\right)}^{R_{w \mid r}\left(r^{*}\right)}\left[1-F_{w}(w)\right] d w d F_{r}(r) \\
+\beta \int_{r^{*}}^{r^{* *}}\left[V(r)-c-V\left(r_{0}\right)\right] F_{r}(r) d r+\beta\left[1-F_{r}\left(r^{* *}\right)\right] c+\varrho c
\end{array}\right\}
\end{aligned}
$$

where $r^{* *}$ denotes the reservation place utility given current place utility equal to, that is, $r^{* *}=r^{*}\left(r^{*}\left(r_{0}\right)\right)$.

The interpretation of the expression is that reservation place utility for a given current place utility is equal to the sum of the current place utility, the flow value of the costs of moving per marginal place utility unit, compensation for the loss in the option value of receiving a national job offer and a residential offer (due to the declining local reservation wage), which is partially offset by the increase in the option value of local job search (due to the declining local reservation wage).

PROOF OF PROPOSITIONS 4 AND 6:

We now turn to derivation of comparative static results for a marginal change in $\alpha_{1}$.

Derivation of $r^{*}$ wrt. $\alpha_{1}$ using the first expression for $r^{*}$ gives the expression

$\frac{\partial r^{*}}{\partial \alpha_{1}}=\frac{1}{a}\left\{\begin{array}{c}-\frac{1}{\rho} \int_{w^{*}\left(r^{*}\right)}^{w^{*}\left(r_{0}\right)}\left[1-F_{w}(w)\right] d w-\frac{\alpha_{1}}{\varrho}\left(\left[1-F_{w}\left(w^{*}\left(r_{0}\right)\right)\right] \frac{\partial w^{*}\left(r_{0}\right)}{\partial \alpha_{1}}-\left[1-F_{w}\left(w^{*}\left(r^{*}\right)\right)\right] \frac{\partial w^{*}\left(r^{*}\right)}{\partial \alpha_{1}}\right) \\ +\frac{\alpha_{2}}{\varrho} \int_{0}^{\bar{r}}\left(\left[1-F_{w}\left(R_{w \mid r}\left(r^{*}\right)\right)\right] \frac{\partial R_{w \mid r}\left(r^{*}\right)}{\partial \alpha_{1}}-\left[1-F_{w}\left(R_{w \mid r}\left(r_{0}\right)\right)\right] \frac{\partial R_{w \mid r}\left(r_{0}\right)}{\partial \alpha_{1}}\right) d F_{r}(r) \\ +\beta \int_{r^{*}}^{r^{* *}}\left(\frac{\partial V(r)}{\partial \alpha_{1}}-\frac{\partial V\left(r^{*}\right)}{\partial \alpha_{1}}\right) d F_{r}(r)\end{array}\right\}$

Similarly, derivation of $r^{*}$ wrt. $\alpha_{1}$ using the second expression for $r^{*}$ gives the expression

$$
\frac{\partial r^{*}}{\partial \alpha_{1}}=\frac{1}{a}\left\{\begin{array}{c}
-\frac{1}{\rho} \int_{w^{*}\left(r^{*}\right)}^{w^{*}\left(r_{0}\right)}\left[1-F_{w}(w)\right] d w-\frac{\alpha_{1}}{\varrho}\left(\left[1-F_{w}\left(w^{*}\left(r_{0}\right)\right)\right] \frac{\partial w^{*}\left(r_{0}\right)}{\partial \alpha_{1}}-\left[1-F_{w}\left(w^{*}\left(r^{*}\right)\right)\right] \frac{\partial w^{*}\left(r^{*}\right)}{\partial \alpha_{1}}\right) \\
+\frac{\alpha_{2}}{\varrho} \int_{0}^{\bar{r}}\left(\left[1-F_{w}\left(R_{w \mid r}\left(r^{*}\right)\right)\right] \frac{\partial R_{w \mid r}\left(r^{*}\right)}{\partial \alpha_{1}}-\left[1-F_{w}\left(R_{w \mid r}\left(r_{0}\right)\right)\right] \frac{\partial R_{w \mid r}\left(r_{0}\right)}{\partial \alpha_{1}}\right) d F_{r}(r) \\
+\beta \int_{r^{*}}^{r^{*}}\left(\frac{\partial V(r)}{\partial \alpha_{1}}-\frac{\partial V\left(r_{0}\right)}{\partial \alpha_{1}}\right) d F_{r}(r)
\end{array}\right\}
$$

Since the two expressions must be equal to each other, it follows that

$$
\frac{\partial V\left(r_{0}\right)}{\partial \alpha_{1}}=\frac{\partial V\left(r^{*}\right)}{\partial \alpha_{1}}
$$

By analogy the above result implies that

where $r^{* * *}=r^{*}\left(r^{* *}\right)$.

$$
\frac{\partial V\left(r^{*}\right)}{\partial \alpha_{1}}=\frac{\partial V\left(r^{* *}\right)}{\partial \alpha_{1}}=\frac{\partial V\left(r^{* * *}\right)}{\partial \alpha_{1}}=\ldots
$$


Using that $\frac{\partial r^{*}}{\partial r_{0}}>0$

$$
\begin{aligned}
& \int_{r^{*}}^{\bar{r}}\left(\frac{\partial V(r)}{\partial \alpha_{1}}-\frac{\partial V\left(r_{0}\right)}{\partial \alpha_{1}}\right) d F_{r}(r) \\
= & \int_{r^{*}}^{r^{* *}}\left(\frac{\partial V(r)}{\partial \alpha_{1}}-\frac{\partial V\left(r_{0}\right)}{\partial \alpha_{1}}\right) d F_{r}(r)+\int_{r^{* *}}^{r^{* * *}}\left(\frac{\partial V(r)}{\partial \alpha_{1}}-\frac{\partial V\left(r_{0}\right)}{\partial \alpha_{1}}\right) d F_{r}(r) \\
& +\ldots+\int_{r^{n *}}^{\bar{r}}\left(\frac{\partial V(r)}{\partial \alpha_{1}}-\frac{\partial V\left(r_{0}\right)}{\partial \alpha_{1}}\right) d F_{r}(r)
\end{aligned}
$$

where $r^{n *} \longrightarrow \bar{r}$ and $r^{n *}$ denotes the reservation place utility value given current place utility $r^{(n-1) *}, n \in Z$. Because $r^{n *} \longrightarrow \bar{r}$, the last term on the right-hand side of Equation (A-21) is approximately equal to zero, and using the result in Equation (A-20) we see that all remaining terms on the right-hand side are zero. Hence,

$$
\int_{r^{*}}^{\bar{r}}\left(\frac{\partial V(r)}{\partial \alpha_{1}}-\frac{\partial V\left(r_{0}\right)}{\partial \alpha_{1}}\right) d F_{r}(r)=0
$$

Derivation of $\frac{\partial V\left(r_{0}\right)}{\partial \alpha_{1}}$ turns out to be useful for establishing the sign of $\frac{\partial r^{*}}{\partial \alpha_{1}}$.

$$
\begin{aligned}
\frac{\partial V\left(r_{0}\right)}{\partial \alpha_{1}} & =\frac{1}{\varrho} \frac{\partial\left(\varrho V\left(r_{0}\right)\right)}{\partial \alpha_{1}} \\
& =\frac{1}{\varrho}\left\{\begin{array}{c}
\frac{1}{\varrho} \int_{w^{*}}^{\bar{w}}\left(1-F_{w}(w)\right) d w-\frac{\alpha_{1}}{\varrho}\left(1-F_{w}\left(w^{*}\right)\right) \frac{\partial w^{*}}{\partial \alpha_{1}} \\
-\frac{\alpha_{2}}{\varrho} \int_{0}^{\bar{r}}\left(1-F_{w}\left(R_{w \mid r}\right)\right) \frac{\partial R_{w \mid r}}{\partial \alpha_{1}} d F_{r}(r) \\
+\beta \int_{r^{*}}^{\bar{r}}\left(\frac{\partial V(r)}{\partial \alpha_{1}}-\frac{\partial V\left(r_{0}\right)}{\partial \alpha_{1}}\right) d F_{r}(r)
\end{array}\right\} \\
& =\frac{1}{\varrho}\left\{\begin{array}{c}
\frac{1}{\varrho} \int_{w^{*}}^{\bar{w}}\left(1-F_{w}(w)\right) d w-\frac{\alpha_{1}}{\varrho}\left(1-F_{w}\left(w^{*}\right)\right) \frac{\partial w^{*}}{\partial \alpha_{1}} \\
-\frac{\alpha_{2}}{\varrho} \int_{0}^{\bar{r}}\left(1-F_{w}\left(R_{w \mid r}\right)\right) \frac{\partial R_{w \mid r}}{\partial \alpha_{1}} d F_{r}(r)
\end{array}\right\} \\
& =\frac{\frac{1}{\varrho^{2}} \int_{w *}^{\bar{w}}\left(1-F_{w}(w)\right) d w}{1+\frac{\alpha_{1}}{\varrho}\left(1-F_{w}\left(w^{*}\right)\right)+\frac{\alpha_{2}}{\varrho} \int_{0}^{\bar{r}}\left(1-F_{w}\left(R_{w \mid r}\right)\right) d F_{r}(r)}>0
\end{aligned}
$$

exploiting that

and

$$
\frac{\partial w^{*}\left(r_{0}\right)}{\partial \alpha_{1}}=\frac{\partial\left(\varrho V\left(r_{0}\right)\right)}{\partial \alpha_{1}}=\varrho \frac{\partial V\left(r_{0}\right)}{\partial \alpha_{1}}
$$

$$
\frac{\partial R_{w \mid r}\left(r_{0}\right)}{\partial \alpha_{1}}=\frac{\partial\left(\varrho V\left(r_{0}\right)-\varrho c\right)}{\partial \alpha_{1}}=\varrho \frac{\partial V\left(r_{0}\right)}{\partial \alpha_{1}}
$$

The numerator of the expression for $\frac{\partial V\left(r_{0}\right)}{\partial \alpha_{1}}$ in Equation (A-23) gives the direct effect of a marginal change in the local job offer arrival rate which is positive, whereas the denominator captures that the indirect effects are negative and smaller than the direct effect in absolute terms, so that the overall effect is positive but less than the direct effect. 
It then follows that

$$
\frac{\partial w^{*}\left(r_{0}\right)}{\partial \alpha_{1}}>0, \frac{\partial R_{w \mid r}\left(r_{0}\right)}{\partial \alpha_{1}}>0
$$

These signs are as expected. The interpretation is that the higher the local job offer arrival rate, the more choosy is it optimal for a person to be wrt. both local and national job acceptance.

In addition, using the results in Equation (A-21), Equation (A-24) and Equation (A-25), Equation (A-18) can be rewritten as

$$
\frac{\partial r^{*}}{\partial \alpha_{1}}=\frac{1}{a}\left\{\begin{array}{c}
-\frac{1}{\rho} \int_{w^{*}\left(r^{*}\right)}^{w^{*}\left(r_{0}\right)}\left[1-F_{w}(w)\right] d w-\frac{\alpha_{1}}{\varrho} \frac{\partial w^{*}}{\partial \alpha_{1}}\left(\left[1-F_{w}\left(w^{*}\left(r_{0}\right)\right)\right]-\left[1-F_{w}\left(w^{*}\left(r^{*}\right)\right)\right]\right) \\
+\frac{\alpha_{2}}{\varrho} \frac{\partial R_{w \mid r}}{\partial \alpha_{1}} \int_{0}^{\bar{r}}\left(\left[1-F_{w}\left(R_{w \mid r}\left(r^{*}\right)\right)\right]-\left[1-F_{w}\left(R_{w \mid r}\left(r_{0}\right)\right)\right]\right) d F_{r}(r)
\end{array}\right\} \lessgtr 0
$$

The sign of the derivative of the reservation place utility wrt. the local job offer arrival rate is ambigous, because the first and third terms on the right-hand side of Equation (A-27) are negative ( since $\frac{\partial R_{w \mid r}\left(r_{0}\right)}{\partial r_{0}}>0$ ), while the second term of the right-hand side is positive (since $\left.\frac{\partial w^{*}\left(r_{0}\right)}{\partial r_{0}}<0\right)$.

\section{ProOF OF PROPOSITIONS 5 AND 7:}

Comparative statics for the national job offer arrival rate are derived analogously. However, let us briefly show the main calculations. Deriving the two different expressions for $r^{*}$ wrt. $\alpha_{2}$ gives to expressions which must be equal to each other, which implies that

and by analogy,

$$
\frac{\partial V\left(r_{0}\right)}{\partial \alpha_{2}}=\frac{\partial V\left(r^{*}\right)}{\partial \alpha_{2}}
$$

Using this result together with the result that

$$
\frac{\partial V\left(r^{*}\right)}{\partial \alpha_{2}}=\frac{\partial V\left(r^{* *}\right)}{\partial \alpha_{2}}=\frac{\partial V\left(r^{* * *}\right)}{\partial \alpha_{2}}=\ldots
$$

$$
\frac{\partial w^{*}\left(r_{0}\right)}{\partial \alpha_{2}}=\frac{\partial R_{w \mid r}\left(r_{0}\right)}{\partial \alpha_{2}}=\varrho \frac{\partial V\left(r_{0}\right)}{\partial \alpha_{2}}
$$

$\frac{\partial V\left(r_{0}\right)}{\partial \alpha_{2}}$ can be shown to be increasing in $\alpha_{2}$

$$
\frac{\partial V\left(r_{0}\right)}{\partial \alpha_{2}}=\frac{\frac{1}{\varrho^{2}} \int_{0}^{\bar{r}} \int_{R_{w \mid r}\left(r_{0}\right)}^{\bar{w}}\left[1-F_{w}(w)\right] d w d F_{r}(r)}{1+\frac{\alpha_{1}}{\varrho}\left[1-F_{w}\left(w^{*}\right)\right]+\frac{\alpha_{2}}{\varrho} \int_{0}^{\bar{r}}\left[1-F_{w}\left(R_{w \mid r}\right)\right] d F_{r}(r)}>0
$$

Hence,

$$
\frac{\partial w^{*}\left(r_{0}\right)}{\partial \alpha_{2}}=\frac{\partial R_{w \mid r}\left(r_{0}\right)}{\partial \alpha_{2}}>0
$$

Finally, using the results in Equation (A-29) and Equation (A-30), it can be shown that 


$$
\frac{\partial r^{*}}{\partial \alpha_{2}}=\frac{1}{a}\left\{\begin{array}{c}
-\frac{\alpha_{1}}{\varrho} \frac{\partial w^{*}}{\partial \alpha_{2}}\left(\left[1-F_{w}\left(w^{*}\left(r_{0}\right)\right)\right]-\left[1-F_{w}\left(w^{*}\left(r^{*}\right)\right)\right]\right) \\
+\frac{\alpha_{2}}{\varrho} \frac{\partial R_{w \mid r}}{\partial \alpha_{2}} \int_{0}^{\bar{r}}\left(\left[1-F_{w}\left(R_{w \mid r}\left(r^{*}\right)\right)\right]-\left[1-F_{w}\left(R_{w \mid r}\left(r_{0}\right)\right)\right]\right) d F_{r}(r) \\
+\frac{1}{\rho} \int_{0}^{\bar{r}} \int_{R_{w \mid r}}^{R_{w \mid r}\left(r_{0}^{*}\right)}\left[1-F_{w}(w)\right] d w d F_{r}(r)
\end{array}\right\} \lessgtr 0
$$

The sign of $\frac{\partial r^{*}}{\partial \alpha_{2}}$ is ambiguous, because the first and the last term on the right-hand side of Equation (A-33) are positive (since $\frac{\partial w^{*}\left(r_{0}\right)}{\partial r_{0}}<0$ ), while the second term on the right-hand side is negative (since $\frac{\partial R_{w \mid r}\left(r_{0}\right)}{\partial r_{0}}>0$ ). 


\section{IZA Discussion Papers}

\begin{tabular}{|c|c|c|c|c|}
\hline No. & Author(s) & Title & Area & Date \\
\hline 910 & $\begin{array}{l}\text { P. Díaz-Vázquez } \\
\text { D. Snower }\end{array}$ & $\begin{array}{l}\text { On-the-Job Training, Firing Costs and } \\
\text { Employment }\end{array}$ & 5 & $10 / 03$ \\
\hline 911 & J. Wagner & $\begin{array}{l}\text { Are Nascent Entrepreneurs Jacks-of-all-Trades? } \\
\text { A Test of Lazear's Theory of Entrepreneurship } \\
\text { with German Data }\end{array}$ & 5 & $10 / 03$ \\
\hline 912 & $\begin{array}{l}\text { D. Checchi } \\
\text { A. Filippin }\end{array}$ & An Experimental Study of the POUM Hypothesis & 1 & $10 / 03$ \\
\hline 913 & $\begin{array}{l}\text { S. Pivnenko } \\
\text { D. DeVoretz }\end{array}$ & $\begin{array}{l}\text { The Recent Economic Performance of Ukrainian } \\
\text { Immigrants in Canada and the U.S. }\end{array}$ & 1 & $10 / 03$ \\
\hline 914 & $\begin{array}{l}\text { A. R. Cardoso } \\
\text { P. Portugal }\end{array}$ & $\begin{array}{l}\text { Bargained Wages, Wage Drift and the Design of } \\
\text { the Wage Setting System }\end{array}$ & 5 & $10 / 03$ \\
\hline 915 & $\begin{array}{l}\text { R. Hujer } \\
\text { C. Zeiss }\end{array}$ & $\begin{array}{l}\text { Macroeconomic Impacts of ALMP on the } \\
\text { Matching Process in West Germany }\end{array}$ & 6 & $10 / 03$ \\
\hline 916 & $\begin{array}{l}\text { S. C. Wolter } \\
\text { S. Mühlemann } \\
\text { J. Schweri }\end{array}$ & $\begin{array}{l}\text { Why Some Firms Train Apprentices and Many } \\
\text { Others Do Not }\end{array}$ & 5 & $10 / 03$ \\
\hline 917 & $\begin{array}{l}\text { R. Euwals } \\
\text { H. Roodenburg }\end{array}$ & $\begin{array}{l}\text { A Note on the Redistributive Effect of } \\
\text { Immigration }\end{array}$ & 1 & $10 / 03$ \\
\hline 918 & $\begin{array}{l}\text { V. Jakobsen } \\
\text { M. Rosholm }\end{array}$ & $\begin{array}{l}\text { Dropping out of School? A Competing Risks } \\
\text { Analysis of Young Immigrants' Progress in the } \\
\text { Educational System }\end{array}$ & 1 & $10 / 03$ \\
\hline 919 & M. Fertig & $\begin{array}{l}\text { The Impact of Economic Integration on } \\
\text { Employment - An Assessment in the Context of } \\
\text { EU Enlargement }\end{array}$ & 2 & $10 / 03$ \\
\hline 920 & $\begin{array}{l}\varnothing . \text { A. Nilsen } \\
\text { K. G. Salvanes } \\
\text { F. Schiantarelli }\end{array}$ & $\begin{array}{l}\text { Employment Changes, the Structure of } \\
\text { Adjustment Costs, and Plant Size }\end{array}$ & 1 & $11 / 03$ \\
\hline 921 & $\begin{array}{l}\text { P. Egger } \\
\text { M. Pfaffermayr } \\
\text { A. Weber }\end{array}$ & $\begin{array}{l}\text { Sectoral Adjustment of Employment: The Impact } \\
\text { of Outsourcing and Trade at the Micro Level }\end{array}$ & 2 & $11 / 03$ \\
\hline 922 & $\begin{array}{l}\text { J. Merz } \\
\text { D. Burgert }\end{array}$ & $\begin{array}{l}\text { Working Hour Arrangements and Working Hours } \\
\text { - A Microeconometric Analysis Based on } \\
\text { German Time Use Diary Data }\end{array}$ & 5 & $11 / 03$ \\
\hline 923 & $\begin{array}{l}\text { U. Dulleck } \\
\text { P. Frijters } \\
\text { R. Winter-Ebmer }\end{array}$ & $\begin{array}{l}\text { Reducing Start-Up Costs for New Firms: The } \\
\text { Double Dividend on the Labour Market }\end{array}$ & 5 & $11 / 03$ \\
\hline 924 & $\begin{array}{l}\text { A. P. Damm } \\
\text { M. Rosholm }\end{array}$ & $\begin{array}{l}\text { Employment Effects of Dispersal Policies on } \\
\text { Refugee Immigrants, Part I: Theory }\end{array}$ & 1 & $11 / 03$ \\
\hline
\end{tabular}

An updated list of IZA Discussion Papers is available on the center's homepage www.iza.org. 